Review

\title{
Oncologic and obstetrical outcomes with fertility-sparing treatment of cervical cancer: a systematic review and meta- analysis
}

\author{
Qing Zhang ${ }^{1,2, *}$, Wenhui Li $^{1,5, *}$, Margaux J. Kanis ${ }^{3}$, Gonghua $\mathbf{Q i}^{1}$, Minghao $\mathrm{Li}^{4}$, \\ Xingsheng Yang ${ }^{1}$ and Beihua Kong ${ }^{1,2}$ \\ ${ }^{1}$ Department of Obstetrics and Gynecology, Qilu Hospital, Shandong University, Ji'nan, Shandong, P.R. China \\ ${ }^{2}$ Gynecology Oncology Key Laboratory, Qilu Hospital, Shandong University, Ji'nan, Shandong, P.R. China \\ ${ }^{3}$ Department of Obstetrics and Gynecology, Division of Gynecologic Oncology, Northwestern University Feinberg School of \\ Medicine, Chicago, IL, USA \\ ${ }^{4}$ Shandong University School of Medicine, Ji'nan, Shandong, P.R. China \\ ${ }^{5}$ Department of Obstetrics and Gynecology, Peking Union Medical College Hospital, Chinese Academy of Medical Sciences \& \\ Peking Union Medical College, Beijing, China \\ * These authors have contributed equally to this work \\ Correspondence to: Beihua Kong, email: kongbeihua@sdu.edu.cn
}

Xingsheng Yang, email: yangxingsheng@sdu.edu.cn

Keywords: conization, radical trachelectomy, early cervical cancer, fertility-sparing treatment, live births

Received: November 04, $2016 \quad$ Accepted: February 06, $2017 \quad$ Published: March 15, 2017

Copyright: Zhang et al. This is an open-access article distributed under the terms of the Creative Commons Attribution License 3.0 (CC BY

3.0), which permits unrestricted use, distribution, and reproduction in any medium, provided the original author and source are credited.

ABSTRACT

OBJECTIVE: The objectives of this study were to evaluate the rates of recurrence, survival and pregnancy, and characterize pregnancy outcomes of early-stage cervical cancer(eCC) treated with fertility-sparing methods such as cervical conization (CON) and radical trachelectomy(RT) with or without pelvic lymphadenectomy.

STUDY DESIGN: This was a meta-analysis of observational studies analyzed by a random-effects model and a meta-regression to assess heterogeneity.

RESULTS: Sixty observational studies encompassing 2,854 patients were included; 17 of which evaluated CON and 43 RT. Three hundred and seventy-five patients were included in the CON group: 176(46.9\%) stage IA1 and $167(44.5 \%)$ stage IB1. In the RT group, 2479 cases were included: 143(6.0\%) stage IA1, $299(12.1 \%)$ stage IA2, $1987(79.9 \%)$ stage IB1. CON was performed in $347(92.5 \%)$ cases, resulting in a recurrence rate of $0.4 \%(95 \% \mathrm{CI}: 0.0 \%-1.4 \%)$, a death rate of $0 \%(0 \%-0 \%)$, a pregnancy rate of $36.1 \%(26.4 \%-46.2 \%)$, a spontaneous abortion rate of $14.8 \%(9.3 \%-21.2 \%)$ and a preterm delivery rate of $6.8 \%(1.5 \%-15.5 \%)$. For the RT group, 2273(91.7\%) underwent successful surgeries with a recurrence rate of $2.3 \%(1.3 \%-3.4 \%)$, a death rate of $0.7 \%(0.3 \%-1.1 \%)$, a pregnancy rate of $20.5 \%(16.8 \%-24.5 \%)$, a spontaneous abortion rate of $24.0 \%(18.8 \%-29.6 \%)$ and a preterm delivery rate of $26.6 \%(19.6 \%-34.2 \%)$. From a subgroup analysis, the recurrence rates for stage IA tumors treated with CON and RT were $0.4 \%(0.0 \%-$ $1.9 \%)$ and $0.7 \%(0.0 \%-2.3 \%)$, respectively; and for stage IB were $0.6 \%(0.0 \%-2.7 \%)$ and $2.3 \%(0.9 \%-4.1 \%)$.

CONCLUSION: Fertility-sparing treatment including CON or RT for eCC is feasible and carefully selected women can preserve fertility and achieve pregnancy resulting in live births. CON seems to result in better pregnancy outcomes than RT with similar rates of recurrence and mortality. 


\section{INTRODUCTION}

Cervical cancer is one of the most common gynecologic malignancy throughout the world. Standard treatment for cervical cancer includes a simple hysterectomy, a radical hysterectomy with pelvic lymphadenectomy or definitive chemoradiation, all of which result in the loss of childbearing ability. Recently, with the improvement of cervical cancer screening, and a trend towards childbearing at an older age, fertility-sparing surgery offers an attractive option for reproductiveaged women. As previously published, $43 \%$ of patients diagnosed with cervical cancer are under the age of 45 [1], and $20-28 \%$ are under the age of $40[2,3]$.

In women with early stage cervical cancer $(\mathrm{eCC})$, it has been proposed that a trachelectomy (RT) or conization procedure (CON) are two options that allow for preservation of fertility. Dargent first published his experience with radical vaginal trachelectomies with a laparoscopic pelvic lymphadenectomy for young women with eCC in 1994 with excellent oncologic outcomes [48].To date, thousands of young patients have undergone trachelectomies resulting in a combined pregnancy rate of $24 \%$ and a recurrence and death rate of $4.2 \%$ and $2.9 \%$, respectively [9]. Alternative approaches including abdominal, laparoscopic and robotic have been adopted.

Although research demonstrates that RT is a safe and feasible technique that can bring excellent clinical results similar to that of the standard surgical procedures for $\mathrm{eCC}$, there are subsequent high rates of first and second trimester abortions and preterm births. In eCC, we know the rate of parametrial metastasis is low, supporting the trend towards performing even more conservative surgery such as a simple conization including a cold knife cone or loop electrical excision procedure (LEEP) with or without pelvic lymphadenectomy. To ascertain the efficacy of these therapies, we conducted a systematic review of observational studies to evaluate recurrence, mortality and pregnancy outcomes in the treatment of $\mathrm{eCC}$ in reproductive-age females, and performed a meta-analysis of their treatment effects.

\section{RESULTS}

\section{Selection and quality analysis of the primary studies}

We identified a total of 2969 articles and excluded 2830 as they did not meet criteria. The remaining 139 articles were reviewed and a further 79 were excluded (see Figure 1).The final analysis included 60 studies, totaling 2,854 patients. Seventeen studies focused on conization with 375 patients, and 43 studies reported on RT with 2479 women [2, 10-68]. The detailed information of the 60 studies is summarized in the Table 1. The methodologic index and qualities of all the studies according to the MINORS checklist are shown in Figure 2.

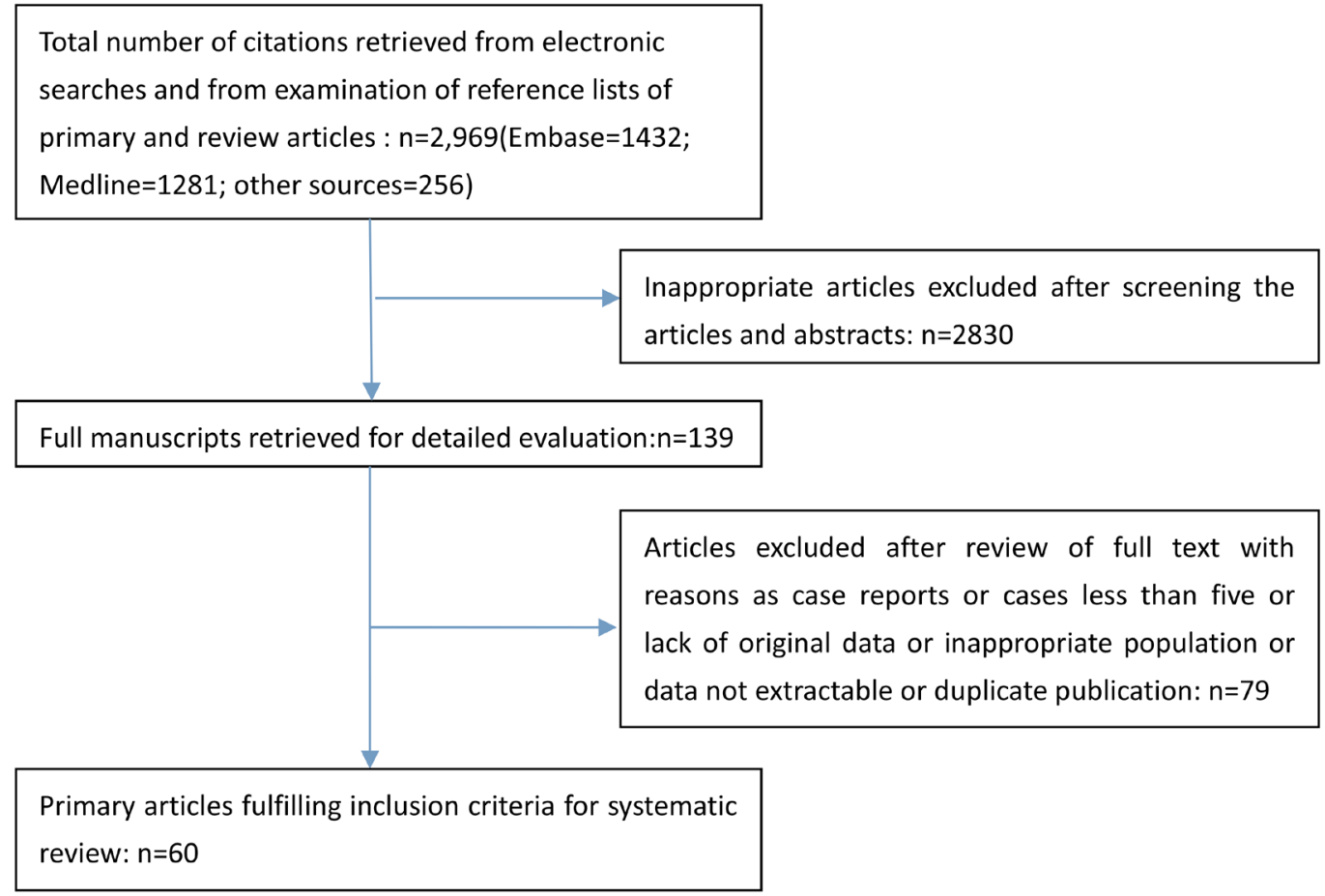

Figure 1: Flowchart of literature selection process. 
Table 1: Characteristic of the studies

\begin{tabular}{|c|c|c|c|c|c|c|c|c|c|}
\hline \multirow{2}{*}{ NO. } & \multirow{2}{*}{ Author,year } & \multirow[b]{2}{*}{ IA1 } & \multicolumn{3}{|c|}{ Stage } & \multirow[b]{2}{*}{ IIA } & \multirow{2}{*}{ Intervention } & \multirow{2}{*}{$\begin{array}{l}\text { Women } \\
\text { Treated }\end{array}$} & \multirow{2}{*}{\begin{tabular}{|l|} 
Follow- \\
up(Median, \\
range inmonths)
\end{tabular}} \\
\hline & & & IA2 & IB1 & IB2 & & & & \\
\hline CON01 & Salihi R et al[10],2015(n=11) & 0 & 0 & 10 & 1 & 0 & conization & 9 & 58 \\
\hline CON02 & Ditto A et al[11], 2015(n=22) & 0 & 6 & 16 & 0 & 0 & conization & 18 & 48.8 \\
\hline CON03 & Fanfani F et al[12], 2014(n=23) & 0 & 7 & 16 & 0 & 0 & conization & 23 & $40(32-125)$ \\
\hline CON04 & Min CC et al[13], 2014(n=21) & 10 & 1 & 9 & 0 & 1 & conization & 21 & $52.6(6-114)$ \\
\hline CON05 & Andikyan $\mathrm{V}$ et al[14], 2014(n=10) & 7 & 0 & 3 & 0 & 0 & conization & 9 & $17(1-83)$ \\
\hline CON06 & Biliatis I et al[15], 2012(n=35) & 0 & 0 & 35 & 0 & 0 & conization & 33 & $56(13-132)$ \\
\hline CON07 & Maneo A et al[16], 2011(n=36) & 0 & 0 & 36 & 0 & 0 & conization & 31 & $66(6-168)$ \\
\hline CON08 & Fagotti A et al[17], 2011(n=17) & 0 & 4 & 13 & 0 & 0 & conization & 13 & $16(8-101)$ \\
\hline CON09 & Baalbergen A et al[18], 2011 $(n=22)$ & 15 & 7 & 0 & 0 & 0 & conization & 20 & $79.9(10-131)$ \\
\hline CON10 & Yahata T et al[19], 2010 $(\mathrm{n}=10)$ & 10 & 0 & 0 & 0 & 0 & conization & 10 & $75(61-127)$ \\
\hline CON11 & Lee SJ et al[20], 2009(n=85) & 85 & 0 & 0 & 0 & 0 & conization & 85 & $81.0(13-127)$ \\
\hline CON12 & Maneo A et al[21], 2008(n=21) & 0 & 0 & 21 & 0 & 0 & conization & 16 & $69(10-124)$ \\
\hline CON13 & Bisseling KCHM et al[22], 2007(n=18) & 16 & 2 & 0 & 0 & 0 & conization & 16 & 72 \\
\hline CON14 & Landoni $\mathrm{F}$ et al[23], 2007(n=11) & 0 & 3 & 8 & 0 & 0 & conization & 11 & $20(7-29)$ \\
\hline CON15 & Itsukaichi $M$ et al[24], 2003(n=7) & 7 & 0 & 0 & 0 & 0 & conization & 7 & $48(27.6-91.2)$ \\
\hline CON16 & Tseng CJ et al[25], 1997(n=12) & 12 & 0 & 0 & 0 & 0 & conization & 12 & $80.4(60-111.6)$ \\
\hline CON17 & Morris M et al[26], 1993(n=14) & 14 & 0 & 0 & 0 & 0 & conization & 13 & $26.5(1-170)$ \\
\hline RT01 & Hauerberg L et al[28], 2015(n=120) & 9 & 8 & 103 & 0 & 0 & RT & 118 & $55.7(5.5-147)$ \\
\hline RT02 & Vieira MA et al[27], 2015(n=100) & 6 & 25 & 69 & 0 & 0 & RT & 83 & $51(10-147)$ \\
\hline RT03 & Jeong-Yeol P et al[2], 2014(n=55) & 0 & 2 & 53 & 0 & 0 & RT & 55 & $37(3-105)$ \\
\hline RT04 & Lanowska M et al[29], 2014(n=20) & 0 & 0 & 15 & 4 & 1 & RT & 18 & $23.1(1-88)$ \\
\hline RT05 & Faber-Swensson AP et al[30], 2014(n=17) & 0 & 4 & 13 & 0 & 0 & RT & 17 & $66(12-156)$ \\
\hline RT06 & Ma LK et al[31], 2014(n=46) & 4 & 4 & 38 & 0 & 0 & RT & 46 & $39.5(1-77)$ \\
\hline RT07 & van Gent MD et al[32], 2014(n=28) & 0 & 3 & 22 & 3 & 0 & RT & 28 & $47.3(6-122)$ \\
\hline RT08 & Park JY et al[33],2014(n=79) & 0 & 4 & 72 & 2 & 1 & RT & 79 & $44(3-105)$ \\
\hline RT09 & Kucukmetin A et al[34], 2014(n=11) & 0 & 0 & 11 & 0 & 0 & RT & 10 & $9(1-20)$ \\
\hline RT09' & $(\mathrm{n}=16)$ & 0 & 0 & 16 & 0 & 0 & RT & 16 & $43(8-110)$ \\
\hline RT10 & Capilna ME et al[35], 2014(n=26) & 0 & 11 & 14 & 1 & 0 & RT & 23 & $20(4-43)$ \\
\hline RT11 & Lintner B et al[36], 2013(n=31) & 0 & 0 & 17 & 14 & 0 & RT & 31 & $90(60-148)$ \\
\hline RT12 & Lu Q et al[37], 2013(n=25) & 0 & 10 & 15 & 0 & 0 & RT & 25 & $66(1-82)$ \\
\hline RT13 & Nishio H et al[38], 2013(n=114) & 9 & 12 & 93 & 0 & 0 & RT & 114 & 33 \\
\hline RT14 & Ebisawa $\mathrm{K}$ et al[39], 2013(n=56) & 0 & 4 & 52 & 0 & 0 & RT & 50 & $60(4-138)$ \\
\hline RT15 & Wethington SL et al[40], 2013(n=29) & 0 & 0 & 29 & 0 & 0 & RT & 9 & $44(1-90)$ \\
\hline $\begin{array}{l}\text { RT16 } \\
\text { RT16, }\end{array}$ & $\begin{array}{c}\text { Cao DY et al[41], 2013(n=77) } \\
(\mathrm{n}=73)\end{array}$ & \begin{tabular}{|l|l|}
13 \\
5 \\
\end{tabular} & $\begin{array}{l}9 \\
10 \\
\end{array}$ & $\begin{array}{l}55 \\
58 \\
\end{array}$ & $\begin{array}{l}0 \\
0 \\
\end{array}$ & $\begin{array}{l}0 \\
0 \\
\end{array}$ & $\begin{array}{l}\text { RT } \\
\text { RT } \\
\end{array}$ & \begin{tabular}{|l|}
71 \\
55 \\
\end{tabular} & \begin{tabular}{|l|}
$24.5(6-91)$ \\
$24.5(6-91)$ \\
\end{tabular} \\
\hline RT17 & Uzan C et al[42], 2013(n=28) & 0 & 6 & 22 & 0 & 0 & RT & 27 & $59(3-132)$ \\
\hline RT18 & Li J et al[43], 2013(n=62) & 0 & 0 & 62 & 0 & 0 & RT & 55 & $30.2(2-108)$ \\
\hline RT19 & Testa $R$ et al[44], 2013 $(n=25)$ & 0 & 6 & 19 & 0 & 0 & RT & 24 & 29.6 \\
\hline RT20 & Muraji M et al[45], 2012(n=8) & 0 & 0 & 8 & 0 & 0 & RT & 7 & $20(2-32)$ \\
\hline RT20' & $(\mathrm{n}=15)$ & 2 & 2 & 11 & 0 & 0 & RT & 12 & $37.5(30-46)$ \\
\hline RT21 & Kim $\mathrm{CH}$ et al[46], 2012(n=105) & 14 & 12 & 79 & 0 & 0 & RT & 77 & 1 \\
\hline RT22 & Persson J et al[47], 2012(n=12) & 4 & 2 & 6 & 0 & 0 & RT & 10 & $76(48-115)$ \\
\hline RT22' & $(\mathrm{n}=13)$ & 4 & 5 & 4 & 0 & 0 & RT & 12 & $24(6-54)$ \\
\hline RT23 & Raju SK et al[48], 2012(n=51) & 0 & 2 & 49 & 0 & 0 & RT & 47 & 96(12-120) \\
\hline RT24 & Nick AM et al[49], 2012(n=37) & 5 & 11 & 21 & 0 & 0 & RT & 32 & $17.0(0.30-64.9)$ \\
\hline RT25 & Wethington SL et al[50], 2012(n=101) & 3 & 8 & 88 & 1 & 1 & RT & 70 & $32(1-124)$ \\
\hline RT26 & Saso $\mathrm{S}$ et al[51], 2012(n=30) & 0 & 2 & 25 & 2 & 1 & RT & 28 & $24(7-113)$ \\
\hline RT27 & Plante $M$ et al[52], 2011 $(n=125)$ & 7 & 29 & 85 & 2 & 2 & RT & 119 & $95(4-225)$ \\
\hline
\end{tabular}




\begin{tabular}{|l|l|l|l|l|l|l|l|l|l|}
\hline RT28 & Li J et al[53], 2011(n=59) & 16 & 7 & 36 & 0 & 0 & RT & 59 & $22.8(1-78)$ \\
\hline RT29 & Marchiole P et al[54], 2011(n=7) & 0 & 0 & 2 & 3 & 2 & RT & 7 & $22(5-49)$ \\
\hline RT30 & Speiser D et al[55], 2011(n=212) & 34 & 47 & 131 & 0 & 0 & RT & 212 & $>12$ \\
\hline RT31 & Yao T et al[56], 2010(n=10) & 0 & 5 & 5 & 0 & 0 & RT & 10 & $(4-68)$ \\
\hline RT32 & Kim JH et al[57], 2010(n=27) & 0 & 0 & 26 & 0 & 1 & RT & 27 & $31(1-58)$ \\
\hline RT33 & Shepherd JH et al[58], 2009(n=142) & 0 & 2 & 139 & 1 & 0 & RT & 142 & 57 \\
\hline RT34 & Olawaiye A et al[59], 2009(n=10) & 1 & 3 & 5 & 0 & 1 & RT & 10 & $28(1-66)$ \\
\hline RT35 & Cibula D et al[60], 2009(n=24) & 0 & 2 & 22 & 0 & 0 & RT & 17 & 21.2 \\
\hline RT36 & Nishio H et al[61], 2009(n=61) & 4 & 8 & 49 & 0 & 0 & RT & 61 & $27(1-67)$ \\
\hline RT37 & Sonoda Y et al[62], 2008(n=40) & 0 & 0 & 40 & 0 & 0 & RT & 40 & $44(3-201)$ \\
\hline RT38 & Milliken DA et al[63], 2008(n=158) & 0 & 4 & 152 & 0 & 2 & RT & 138 & $/$ \\
\hline RT39 & Pareja FR et al[64], 2008(n=15) & 0 & 3 & 12 & 0 & 0 & RT & 15 & $32(5-32)$ \\
\hline RT40 & Shepherd JH et al[65], 2006(n=123) & 0 & 2 & 121 & 0 & 0 & RT & 112 & $45(1-120)$ \\
\hline RT41 & Chen Y et al[66], 2006(n=16) & 3 & 7 & 6 & 0 & 0 & RT & 16 & $28.2(8-50)$ \\
\hline RT42 & Ungar L et al[67], 2005(n=30) & 0 & 10 & 15 & 5 & 0 & RT & 29 & $32(14-75)$ \\
\hline RT43 & Schlaerth JB et al[68], 2003(n=10) & 0 & 8 & 2 & 0 & 0 & RT & 10 & 10 persons $\geq 24$, \\
\hline
\end{tabular}

\section{Patient characteristics}

The median age of patients included ranged from 27 to 39 years old. The length of follow-up was 9-95 months. Based on NCCN guidelines, we considered an appropriate follow-up to be at least 5 years, although only 14 of the 60 published results that included this length of surveillance. In 37 papers, patients underwent the diagnostic imaging such as MRI, CT or PET to exclude distant disease and lymphatic metastasis. The qualities of all the studies according to the MINORS checklist have been shown in Figure 2.
Prognosis and pregnancy outcome of fertilitysparing treatment by conization

The 17 CON studies identified 375 cases including $176(46.93 \%)$ women with stage IA1, 30(8.00\%) with stage IA2, 167(44.53\%) with stage IB1, 1(0.27\%) with stage IB2, 1(0.27\%) with stage IIA. 347 (92.5\%) successfully underwent the fertility-sparing treatment. The median follow-up in this group ranged from 16 to 81 months and $82.4 \%(14 / 37)$ were followed for more than 2 years.

Among the 347 who underwent conization, 4 relapsed with a pooled proportion and its $95 \%$ CIs from

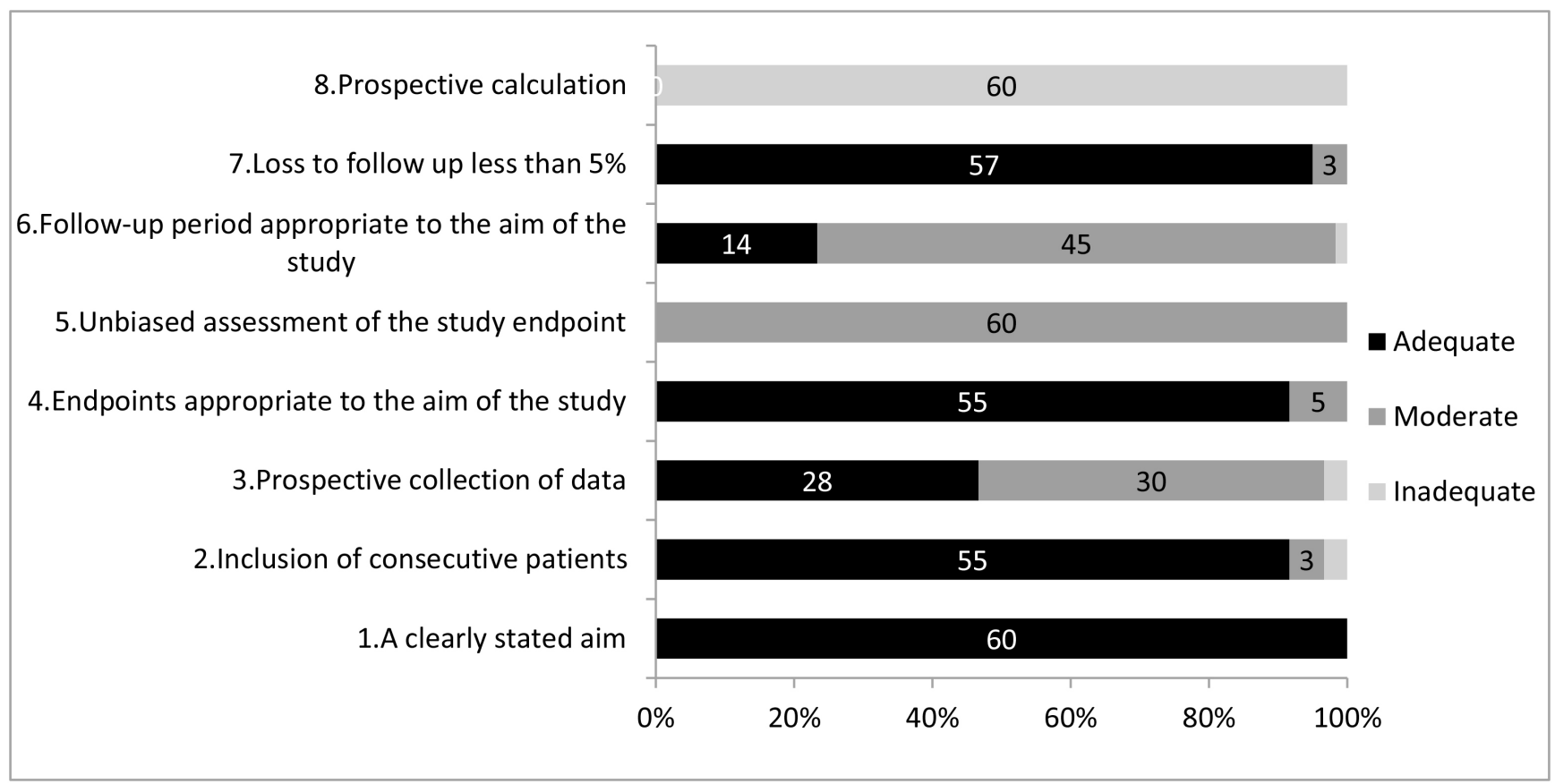

Figure 2: Quality assessment. 
Table 2: Results of the proportions from forest plots

\begin{tabular}{|c|c|c|c|c|c|c|}
\hline Proportions & $\begin{array}{l}\text { Number of } \\
\text { studies }\end{array}$ & $\begin{array}{l}\text { Test for } \\
\text { Heterogeneity }\left(I^{2}\right)\end{array}$ & $\begin{array}{l}\text { Test for } \\
\text { Heterogeneity: } \\
\text { (p value of } Q \text { test) } \\
\end{array}$ & $\begin{array}{l}\text { Fixed effect model } \\
\text { (effect size,95\%CI) }\end{array}$ & $\begin{array}{l}\text { Random effects model } \\
\text { (effect size,95\%CI) }\end{array}$ & $p$ \\
\hline $\begin{array}{l}\text { recurrence rate of } \\
\text { appendix involved }\end{array}$ & 63 & $49.7 \%$ & $<0.0001$ & $0.0231[0.0176 ; 0.0294]$ & $0.0173[0.0102 ; 0.0263]$ & 0.0116 \\
\hline In $\mathrm{CON}$ & 17 & $0.0 \%$ & 0.8427 & $0.0042[0.0002 ; 0.0137]$ & $0.0042[0.0002 ; 0.0137]$ & \\
\hline In RT & 46 & $55.2 \%$ & $<0.0001$ & $0.0277[0.0211 ; 0.0351]$ & $0.0225[0.0133 ; 0.0341]$ & \\
\hline $\begin{array}{l}\text { death rate of } \\
\text { appendix involved }\end{array}$ & 62 & $0.0 \%$ & 0.5428 & 0.0055 [0.0030; 0.0089$]$ & 0.0055 [0.0030; 0.0089$]$ & 0.0188 \\
\hline In CON & 17 & $0.0 \%$ & 0.9994 & $0.0003[0.0000 ; 0.0047]$ & $0.0003[0.0000 ; 0.0047]$ & \\
\hline In RT & 45 & $11.9 \%$ & 0.2485 & $0.0071[0.0039 ; 0.0111]$ & $0.0065[0.0032 ; 0.0108]$ & \\
\hline $\begin{array}{l}\text { pregnancy rate of } \\
\text { appendix involved }\end{array}$ & 63 & $77.5 \%$ & $<0.0001$ & $0.2329[0.2169 ; 0.2492]$ & $0.2381[0.2018 ; 0.2765]$ & 0.0011 \\
\hline In CON & 17 & $71.0 \%$ & $<0.0001$ & $0.3125[0.2649 ; 0.3623]$ & $0.3607[0.2648 ; 0.4625]$ & \\
\hline In RT & 46 & $78.3 \%$ & $<0.0001$ & $0.2214[0.2046 ; 0.2387]$ & $0.2054[0.1681 ; 0.2454]$ & \\
\hline $\begin{array}{l}\text { abortion rate of } \\
\text { appendix involved }\end{array}$ & 60 & $55.6 \%$ & $<0.0001$ & $0.2529[0.2255 ; 0.2814]$ & $0.2056[0.1612 ; 0.2539]$ & 0.0182 \\
\hline \begin{tabular}{c|} 
In CON \\
\end{tabular} & 17 & $39.8 \%$ & 0.0511 & $0.1475[0.0934 ; 0.2116]$ & $0.1196[0.0558 ; 0.2032]$ & \\
\hline In RT & 44 & $55.5 \%$ & $<0.0001$ & $0.2732[0.2427 ; 0.3048]$ & $0.2395[0.1875 ; 0.2957]$ & \\
\hline $\begin{array}{ll}\text { preterm } & \text { delivery } \\
\text { rate of appendix } \\
\text { involved }\end{array}$ & 57 & $75.5 \%$ & $<0.0001$ & $0.2851[0.2559 ; 0.3152]$ & $0.2134[0.1537 ; 0.2801]$ & 0.0020 \\
\hline In CON & 17 & $40.3 \%$ & 0.0653 & $0.0778[0.0320 ; 0.1413]$ & $0.0679[0.0148 ; 0.1553]$ & \\
\hline In RT & 46 & $75.6 \%$ & $<0.0001$ & $0.3145[0.2827 ; 0.3471]$ & $0.2660[0.1961 ; 0.3423]$ & \\
\hline $\begin{array}{l}\text { recurrence rate of } \\
\text { stage IA }\end{array}$ & 31 & $0.0 \%$ & 0.9748 & $0.0054[0.0005 ; 0.0152]$ & $0.0054[0.0005 ; 0.0152]$ & 0.7757 \\
\hline In CON & 11 & $0.0 \%$ & 0.9032 & $0.0044[0.0000 ; 0.0186]$ & $0.0044[0.0000 ; 0.0186]$ & \\
\hline In RT & 20 & $0.0 \%$ & 0.8893 & $0.0065[0.0001 ; 0.0230]$ & $0.0065[0.0001 ; 0.0230]$ & \\
\hline $\begin{array}{l}\text { recurrence rate of } \\
\text { stage IB }\end{array}$ & 39 & $49.8 \%$ & 0.0003 & $0.0250[0.0164 ; 0.0354]$ & $0.0190[0.0082 ; 0.0341]$ & 0.2616 \\
\hline In CON & 9 & $7.5 \%$ & 0.3727 & $0.0063[0.0000 ; 0.0253]$ & $0.0064[0.0000 ; 0.0270]$ & \\
\hline In RT & 30 & $53.8 \%$ & 0.0003 & $0.0293[0.0193 ; 0.0413]$ & 0.0226 [0.0094; 0.0413$]$ & \\
\hline
\end{tabular}

the forest plot to be $0.4 \%(95 \% \mathrm{CI}$ : $0.0 \%-1.4 \%$ ) (sFigure 1). The value for $\mathrm{I}^{2}$ test was $0 \%$ indicating no significant heterogeneity between the $\operatorname{studies}(P>0.05)$. Diseasespecific mortality after conization was $0 \%(0 \%-0 \%)$ with no obvious heterogeneity $\left(\mathrm{I}^{2}=0 \%, \mathrm{P}>0.05\right)$.

Meta-analysis of the 37 studies reporting pregnancy results found that 113 young women achieved at least 1 pregnancy after conization resulting in a pregnancy rate of $36.1 \%(26.4 \%-46.2 \%)$ with high heterogeneity $\left(\mathrm{I}^{2}=\right.$ $71.0 \%, P<0.05)$. Among all patients who conceived, the spontaneous abortion rate was $14.8 \%(9.3 \%-21.2 \%)$ with moderate heterogeneity $\left(\mathrm{I}^{2}=39.8 \%, P>0.05\right)$. Similarly, we obtained a preterm delivery rate of $6.8 \%(1.5 \%-15.5 \%)$ with moderate heterogeneity $\left(\mathrm{I}^{2}=40.3 \%, P>0.05\right)$.

\section{Prognosis and pregnancy outcome of fertility- sparing treatment by $R T$}

We enrolled 43 articles about RT(RT group) with 2479 cases including 143(6.0\%)women with stage IA1, 299(12.1\%) with stage IA2, 1987(79.9\%) with stage IB1. 2273 of 2479 patients $(91.7 \%)$ received the fertilityconserving treatment. In these 43 studies, patients were followed up over time with the average ranging from 9 to 96 months and $81.4 \%(35 / 47)$ was more than 2 years.

Meta-analysis of the 43 studies with fertilityconservative treatment by RT amounted to the pooled estimates of the corresponding rates and 95\% CIs from the forest plots shown in Figure 3B-5B and sFigure 1-04. The relapse and dead cases were reported in all articles and concluded their respective pooled occurrence rates in the forest plots to be $2.3 \%(1.3 \%-3.4 \%)$ with obvious heterogeneity and $0.7 \%(0.3 \%-1.1 \%)$ with minor heterogeneity. In these 43 studies indicated, we found 531 women after conservative treatment conceive at least once, which amounted to a pooled pregnancy rate of $20.5 \%(16.8 \%-24.5 \%)$ from the forest plot. The value of $\mathrm{I}^{2}$ test was $78.3 \%$, indicating the existence of heterogeneity. There were 805 pregnancies recorded during followup, from which several cases had an abortion in first- or second-trimester, amounting to a pooled abortion rate of $24.0 \%(18.8 \%-29.6 \%)$ by meta-analysis with obvious heterogeneity between studies $\left(\mathrm{I}^{2}=55.5 \%, P<0.05\right)$. As well, the preterm delivery rate was computed in the forest plot to be $26.6 \%(19.6 \%-34.2 \%)$ finally, with $\mathrm{I}^{2}=75.6 \%(P$ $<0.05)$. The results of the two groups were concluded in table 2 . 


\section{Prognosis of patients with stage IA or IB after conization and $R T$}

Eleven studies including 191 women were enrolled in the analysis of prognosis result by conization with stage IA. As shown in Figure 4A, we obtained pooled proportion and $\mathrm{CIs}$ by mete-analysis from the forest plots. Two cases of recurrence amounted to a recurrent rate of $0.4 \%(0.0 \%$ $1.9 \%)$ with no obvious heterogeneity $\left(\mathrm{I}^{2}=0, P>0.05\right)$.
Meanwhile, we included 20 studies with 188 patients of stage IA enrolled in the analysis of prognosis by RT, which amounted to a recurrent rate in RT group of $0.7 \%(0.0 \%$ $2.3 \%)$ with no obvious heterogeneity $\left(\mathrm{I}^{2}=0, P>0.05\right)$.

For stage IB, 148 patients( $(99 \%$ IB1) in CON group were included for assessment of prognosis by conization. In Figure 5A, 3 cases of recurrence amounted to a recurrence rate of $0.6 \%(0.0 \%-2.7 \%)$ with minor heterogeneity $\left(\mathrm{I}^{2}=7.5 \%, P>0.05\right)$. And we enrolled 30 studies with 898 patients of stage IB(97\% IB1) in the

A

Type $=$ CON

Study

Salini $R$ et al, $2015(n=11)$

Ditto A et al, 2015(n=22)

Min CC et al, 2014 $(n=21)$

Andikyan V et al, $2014(n=10)$

Biliatis I et al, 2012 $(n=35)$

Maneo A et al, $2011(n=36)$
Fagotti A et al, $2011(n=17)$

Fagotti $A$ et al, $2011(n=17)$
Baalbergen $A$ et al, $2011(n=22)$

Yahata T et al, $2010(n=10)$

Lee SJ et al, 2009 $(n=85)$

Bisseling KCHM et al, $2007(n=18)$

Landoni F et al, 2007( $(\mathrm{n}=11)$

Itsukaichi $\mathrm{M}$ et al, $2003(\mathrm{n}=7)$

Morris M et al, $1993(n=14)$

Fixed effect model

Random effects model

Heterogeneity: 1 -squared $=71 \%$, tau-squared $=0.0315, p<0.0001$

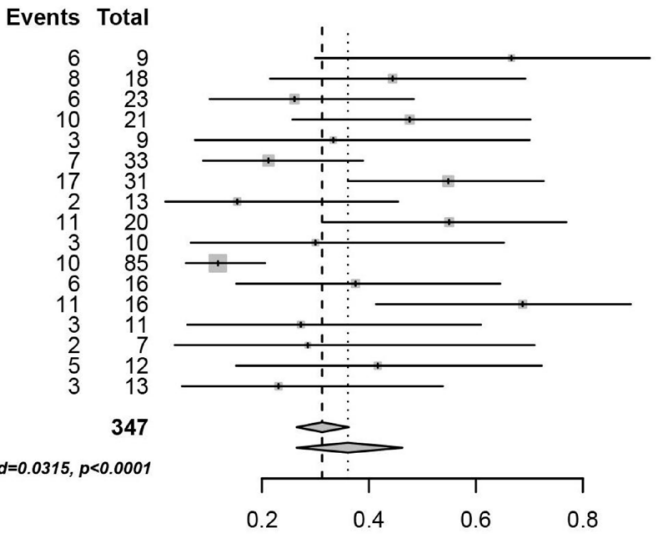

B

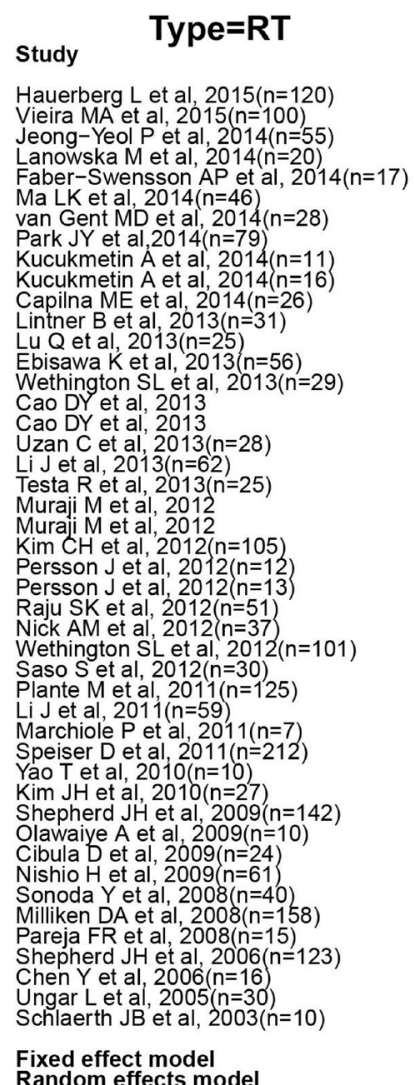

Random effects model

Heterogeneity: 1 -squared $=78.3 \%$, au-squared $=0.0186, p<0.000$

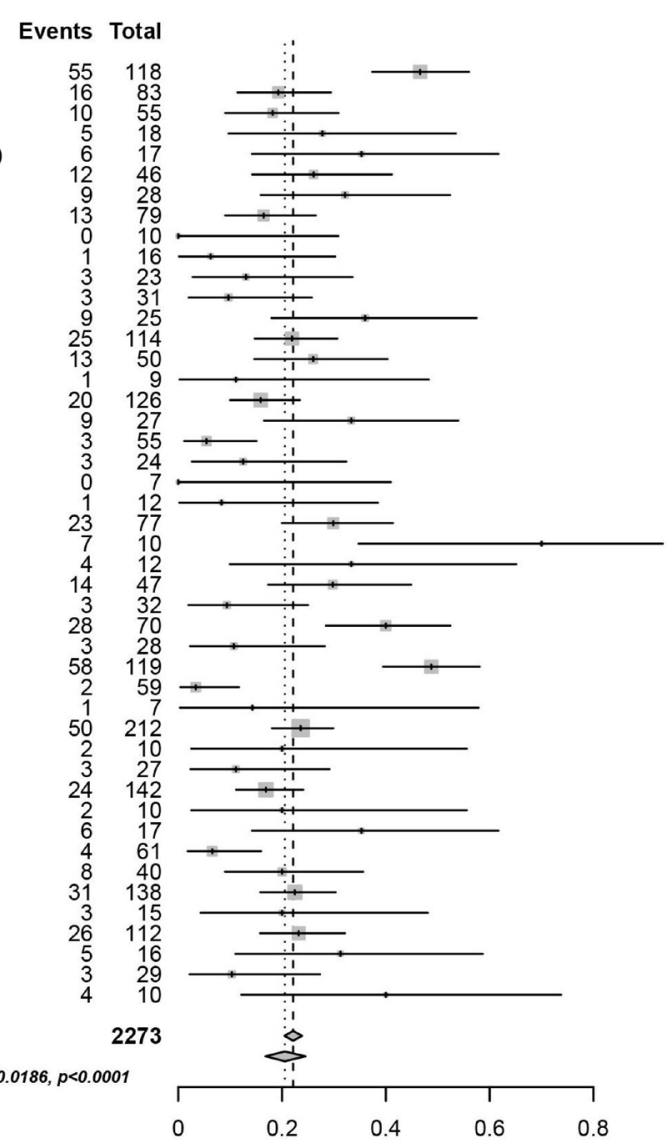

Proportion

\subsection{6}

0.18

0.2778

0.2609
0.3214

0.3214
0.1646

0.0000

0.0625

0.1304

0.3600
0.2193

0.2193
0.2600

0.1111

0.1587
0.3333

0.0545
0.1250

0.0000

0.0833
0.2987

0.7000

0.3333
0.2979

0.0938

0.4000
0.1071

0.4874

0.0339
0.1429
0.2358

0.2358
0.2000

0.1111

0.2000

0.3529

0.2000

0.2000

0.2321

0.1034
0.4000

0.9251

$5 \%-\mathrm{Cl}$ W(fixed) W(random)

0.2214

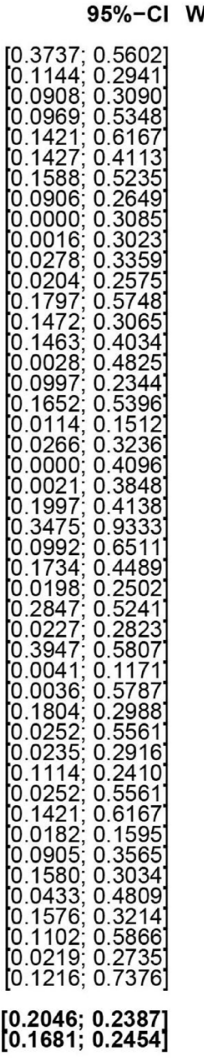

\begin{tabular}{ll}
$5.2 \%$ & $2.9 \%$ \\
$3.7 \%$ & $2.8 \%$ \\
$2.4 \%$ & $2.6 \%$ \\
$0.8 \%$ & $1.8 \%$ \\
$0.7 \%$ & $1.8 \%$ \\
$2.0 \%$ & $2.5 \%$ \\
$1.2 \%$ & $2.2 \%$ \\
$3.5 \%$ & $2.7 \%$ \\
$0.4 \%$ & $1.4 \%$ \\
$0.7 \%$ & $1.7 \%$ \\
$1.0 \%$ & $2.0 \%$ \\
$1.4 \%$ & $2.2 \%$ \\
$1.1 \%$ & $2.1 \%$ \\
$5.0 \%$ & $2.9 \%$ \\
$2.2 \%$ & $2.5 \%$ \\
$0.4 \%$ & $1.3 \%$ \\
$5.5 \%$ & $2.9 \%$ \\
$1.2 \%$ & $2.1 \%$ \\
$2.4 \%$ & $2.6 \%$ \\
$1.1 \%$ & $2.1 \%$ \\
$0.3 \%$ & $1.1 \%$ \\
$0.5 \%$ & $1.5 \%$ \\
$3.4 \%$ & $2.7 \%$ \\
$0.4 \%$ & $1.4 \%$ \\
$0.5 \%$ & $1.5 \%$ \\
$2.1 \%$ & $2.5 \%$ \\
$1.4 \%$ & $2.3 \%$ \\
$3.1 \%$ & $2.7 \%$ \\
$1.2 \%$ & $2.2 \%$ \\
$5.2 \%$ & $2.9 \%$ \\
$2.6 \%$ & $2.6 \%$ \\
$0.3 \%$ & $1.1 \%$ \\
$9.3 \%$ & $3.0 \%$ \\
$0.4 \%$ & $1.4 \%$ \\
$1.2 \%$ & $2.1 \%$ \\
$6.2 \%$ & $2.9 \%$ \\
$0.4 \%$ & $1.4 \%$ \\
$0.7 \%$ & $1.8 \%$ \\
$2.7 \%$ & $2.6 \%$ \\
$1.8 \%$ & $2.4 \%$ \\
$6.1 \%$ & $2.9 \%$ \\
$0.7 \%$ & $1.7 \%$ \\
$4.9 \%$ & $2.9 \%$ \\
$0.7 \%$ & $1.7 \%$ \\
$1.3 \%$ & $2.2 \%$ \\
$0.4 \%$ & $1.4 \%$ \\
$100 \%$ & \\
\hline & \\
\hline & $100 \%$ \\
& \\
&
\end{tabular}

Figure 3: A. Pregnancy rates of conization. B. Pregnancy rates of RT. 
analysis of prognosis by RT(Figure 5B). The recurrence rate in RT group obtained from forest plot were $2.3 \%(0.9 \%-4.1 \%)$ with obvious heterogeneity $\left(\mathrm{I}^{2}=53.8 \%\right.$, $P<0.05)$. The results by conization or RT in different stages were summarized in Table 2.

\section{DISCUSSION}

Fertility preservation and quality of life are becoming increasingly important concerns of young women with cervical cancer and less invasive surgical procedures have become a potential solution. The results of this review demonstrate that conization has similar oncologic outcomes to RT for eCC patients especially those before stage IB1 to preserve fertility. Furthermore, obstetrical outcomes are very encouraging, underscoring the role of conization in these patients.

What's more, the minimally invasive surgery have confirmed the advantages of a reduced length of hospital stay, less blood loss, lower analgesic requirements during the post operative period, a decreased rate of complications, and an early recovery of physiological functions [69, 70]. Numerous researches have proved that RT can obtain a similar death rate with radical hysterectomy in low-risk eCC to be a safe alternative for fertility conserving. Some surveys shown that recurrence rate of Dargent's operation was reported to be $4.2 \%$ $4.7 \%$ and mortality rate between $2.8 \%$ and $3.0 \%$ [71, 72]. In 2013, Plante M reviewed articles and generalized the recurrence rate of ART and LRT to be $4 \%$ and $7 \%$ respectively. In our review, we do a meta-analysis and it shows a low recurrence rate of $2.3 \%(1.3 \%-3.4 \%)$ and mortality of $0.7 \%(0.3 \%-1.1 \%)$ in RT group, which are close to the aforesaid statistics. However, although RT is quite effective from the oncologic point of view, the execution of this procedure to maintain pregnancy competence for young eCC patients responds a bit undesirable conception outcome with a high risk of firstand second-trimester miscarriage and preterm delivery $[68,73-75]$. There have been more than 300 pregnancies reported after RT in the literature, with a live-birth rate of $68 \%$ [76]. But literature by Rob et al showed that pregnancy loss or delivery before 32 weeks was as high as $44 \%$ for VRT and $38 \%$ for ART [71], and Pareja et al. in 2015 concluded the global pregnancy rates of $16.2 \%$ in ART and 24\% in VRT [77]. The data seem to range broadly because it may be calculated in different ways or influenced by the number of women attempting to conceive among patients after conservative procedure. With respect to our research, we did a meta-analysis and

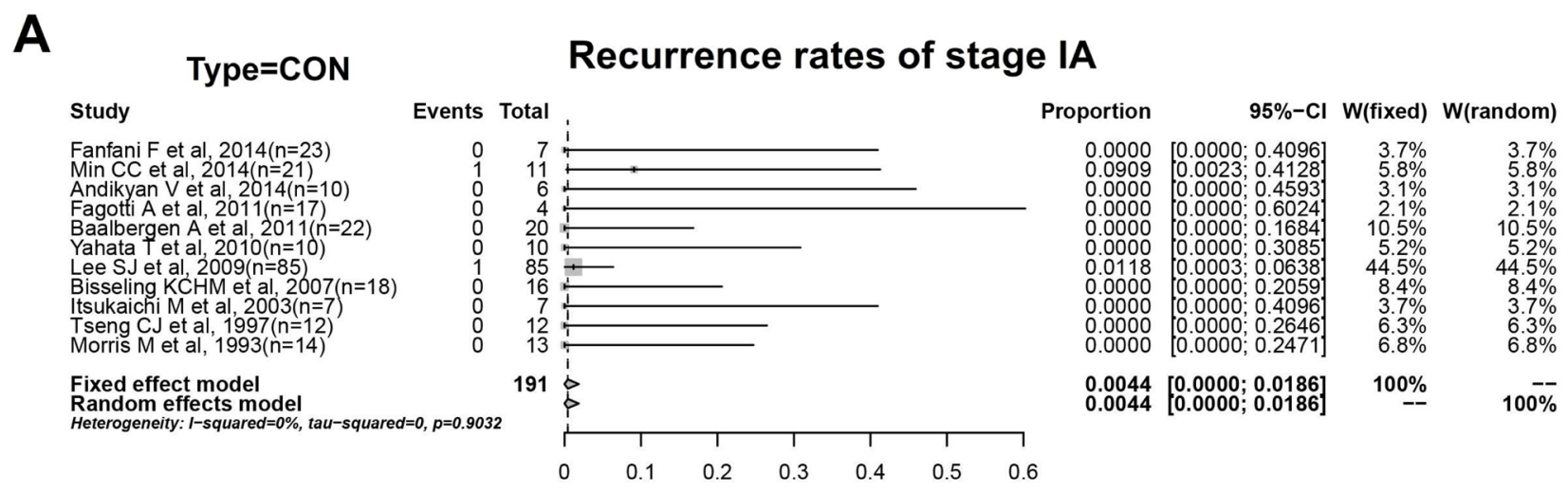

B
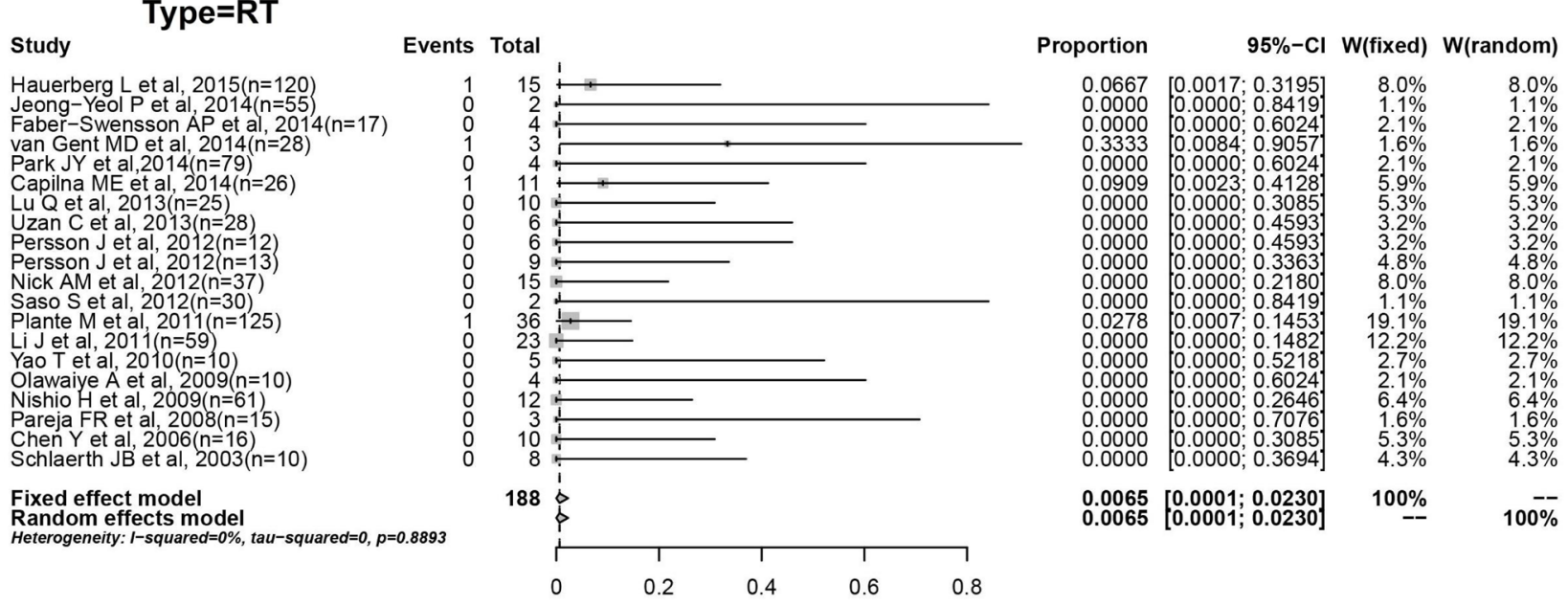

Figure 4: A. Recurrence rates of conization with stage IA. B. Recurrence rates of RT with stage IA. 
the aggregated rates of RT in miscarriage and preterm labor are $24.0 \%(18.8 \%-29.6 \%)$ and $26.6 \%(19.6 \%-34.2 \%)$ separately with a pooled pregnancy rate of $20.5 \%(16.8 \%$ $24.5 \%$ ) in all fertility-conserved ones.

Compared with results of $\mathrm{RT}$, conization is more likely to be encouraging in the aspects of pregnancy possibility and pregnancy ending due to less parametrial excision and mild damage to pelvic floor, which might benefit decreasing rates of pregnancy loss. But information about conization security and pregnancy outcome is still scant. For many retrospective researches have revealed that in small-volume, low-risk, early-stage cervical cancer (defined as measuring $<2 \mathrm{~cm}$ with $<50 \%$ stromal invasion), the probability of parametrial extension is very low and even less than $1 \%$ concluded from a 1000 patient retrospective review analysis, which testified indirectly the security of conization [78]. In addition, previous studies have shown that patients who undergo a RT have no residual disease accounts for approximately $60 \%$ in their surgical specimen, suggesting that perhaps those patients could have been treated with less radical surgery
[79]. Plante also pointed that albeit no sufficient and mature data were available so far, large conization(in lowrisk patients) seem to support oncologic safety of radical trachelectomy, improving reproductive outcomes. Ditto et al. evaluated the safety, feasibility and effectiveness of conization plus laparoscopic pelvic lymphadenectomy in eCC women of stage IA2-IB1 and concluded 5-year disease-free and overall survival rates of $85.9 \%$ and $93.7 \%$, respectively with a $44 \%$ spontaneous pregnancy rate [11].

In addition, Lindsay et al reported encouraging oncologic (recurrence rate, 5\%) and reproductive(live birth rate, $35 \%$ ) outcomes undergoing large loop excision of the transformation zone and laparoscopic pelvic lymph node dissection [80]. In our meta-analysis, the 17 essays referred have low recurrence rates ranging from 0 to $11 \%$, summarized to be $0.4 \%(0.0 \%-1.4 \%)$, with corresponding death rate of $0 \%(0 \%-0 \%)$, which shows quite ideal results close to those of RT procedure. And moreover, to get rid of the influence of stages on prognosis, we did subgroups with stage IA and IB(mainly IB1) which also showed great

A

\section{Type $=\mathrm{CON} \quad$ Recurrence rates of stage IB}

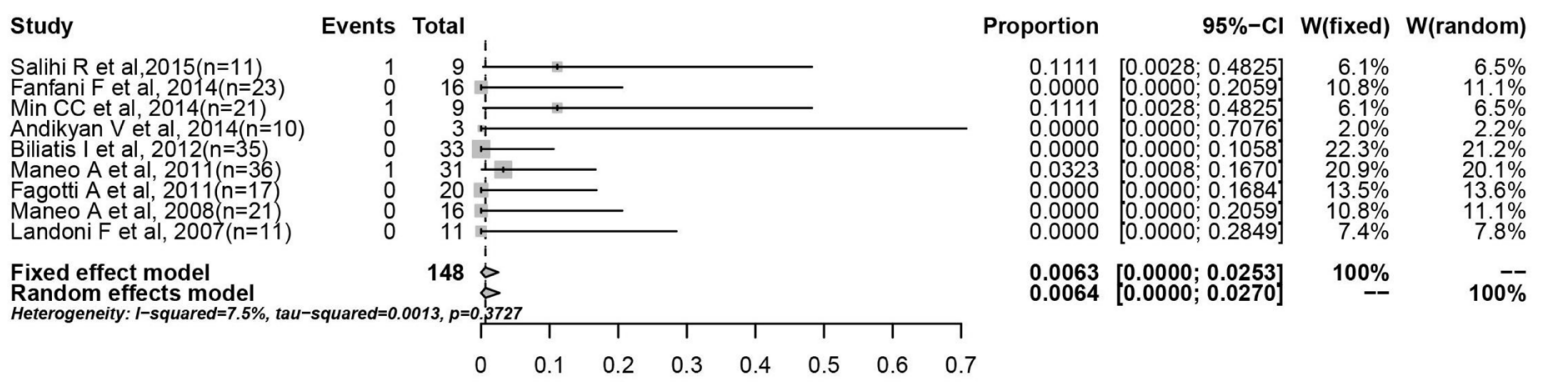

B

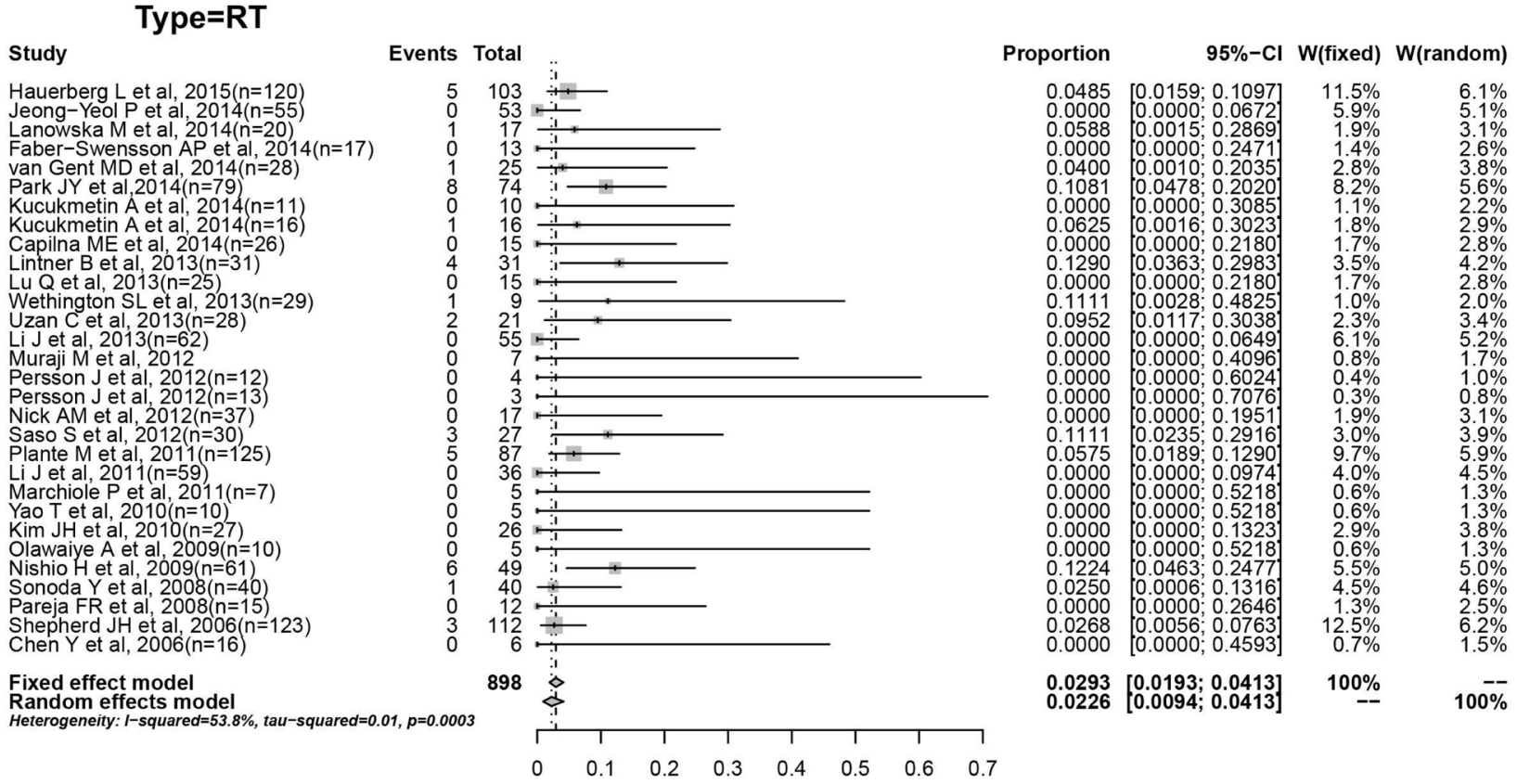

Figure 5: A. Recurrence rates of conization with stage IB. B. Recurrence rates of RT with stage IB. 
outcome in CON group by recurrent rates compared with RT. But what we want to emphasize here is that conization management seem to receive much better results than RT in pregnancy incidence $36.1 \%(26.4 \%-46.2 \%)$, and the miscarriage and premature birth rate of conization are much lower for $14.8 \%(9.3 \%-21.2 \%)$ and $6.8 \%(1.5 \%$ $15.5 \%$ ) respectively among all reproductive-conserved patients.

However, as we reviewed large amounts of articles, young patients with eCC treated by RT or even conization as fertility-sparing treatment must be screened out with strict inclusion criteria probably referring to the age of patients, stages, histological subtype, tumor volume, depth of invasion, lymphatic spread, or parametrial involvement. Most oncologists maintain that tumors measuring < $2 \mathrm{~cm}$ are one of the key requirements, particularly for conization, to guarantee removal of all tumor. Some researchers believed patients with tumors larger than 2 $\mathrm{cm}$ had a higher recurrent rate than those smaller than $2 \mathrm{~cm}$, and when LVSI are positive, wider resection are needed; for patients with tumors larger than $2 \mathrm{~cm}$, ART or neoadjuvant chemotherapy are more recommended for conservative treatment to gain a similar recurrent rate. But on the other side, some studies showed unclear difference with prognosis under different tumor volume and LVSI state. Owing to the limited articles and information we referred and absence of randomized trials comparing different therapeutic conservative strategies, we didn't analyze the different effect of stages, tumor volume, or other factors such as chemotherapy and in our study. But there are still some patients with larger tumors showing a favorable outcome after conservative surgeries and the "one-size-fits-all" concept is gradually to be challenged. This will be likely to be completed more broadly as the effectiveness of neoadjuvant chemotherapy are proved and applied one day. We included 20 papers referred to more than 300 patients with tumors larger than $2 \mathrm{~cm}$ which couldn't be seperated for detailed discussion. In addition, application of chemotherapy after surgery was mentioned in several articles, primarily for patients after conization. 8 articles referred to patients receiving neoadjuvant chemotherapy were included in CON group which was believed to ensure the safety of conservative treatment and all studies showed ideal outcome according to the limited patients. But restricted by limited information, it couldn't be talked by subgroups. For limited excision, some surgeons hold the opinion that patients with increased risk of recurrence need to receive chemotherapy after conization, such as positive margin, tumor measuring $>2 \mathrm{~cm}$, deep stromal infiltration. And researchers [13] suggest no effect of chemotherapy on ovarian function in short follow-up.

However, the recurrence rates during follow-up are concerning and many factors relevant have not been discussed in this review to explain it further. And our study are carried on by a meta-analysis based on respective rates rather than $\mathrm{RCTs}$ which brings confounding effects and weakens the reliability and we only analyze patients without distinguishing tumors larger or smaller than $2 \mathrm{~cm}$, adjuvant therapy or not, histological types for detailed discussion. Despite numerous studies confirming the oncologic and obstetrical validity of conization, and similarly, RT, additional prospective cohort studies are required.

\section{COMMENT}

In our review, we found that both $\mathrm{CON}$ and $\mathrm{RT}$ with or without lymphadenectomy are encouraging as a fertility-sparing treatment for eCC, especially in stage IAIB1, according to the low relapse rates of conization and RT, and an additional encouraging proportion of women managed to achieve pregnancy. For patients with stage IA, conization seems much suitable for lower abortion rate and preterm delivery rate, resulted from the limited and minor injury to the cervical and parametrium, and great oncologic outcome. For stage IB, particularly IB1, patients should be evaluated comprehensively before conservative treatment and conization with pelvic lymphadenectomy may be a suitable option.

\section{MATERIALS AND METHODS}

\section{Search strategy and selection criteria}

The study population in this review included women with eCC (predominantly International Federation of Gynecology and Obstetrics stage I) who desired to maintain fertility. Patients underwent fertility-sparing therapies including conization or RT with or without pelvic lymphadenectomy. The primary outcome measures were disease recurrence, mortality and pregnancy outcomes. Electronic searches using Medline, the Cochrane Library and Embase were performed for studies published in English between 1993 and September 2015. The terms used in the search were "cervical cancer", "radical trachelectomy", "conization", "fertility sparing", "oncological and obstetrical outcome". Reference lists of all articles identified by our searches were reviewed to identify potential missing studies or unpublished data.

Articles were selected if the patients had eCC defined as stage IA-IB according to FIGO 2009 staging system, documented pathology review, underwent conization or RT for conservative therapy, and the results described the recurrence, mortality and pregnancy outcomes. Patients in studies were aged under 45 years old without evidence of infertility and other malignancies. We excluded case reports, review articles, series updates and series with less than five patients. All articles were checked independently by 2 reviewers. The references 
for retrieved articles together with the proceedings of relevant conferences were hand-searched to identify other potentially eligible publications that met the predefined selection criteria for inclusion in the analysis and missed by the initial search. For overlap or duplicate cases, the most recent or the most comprehensive publication was used. Disagreements were resolved by consensus or arbitration by a third reviewer. An additional two reviewers were used for the quality assessment. The Methodological Index for Non-Randomized Studies(MINORS) was used to evaluate the quality of the included studies [81].

\section{Data extraction and analysis}

In this review, pregnancy rate was defined as the number of women who conceived successfully divided by the number of total of women who retained their fertility during follow-up. We counted the number of patients with recurrent disease and dead women to assess the oncologic outcomes of the two conservative surgeries. We calculated spontaneous abortion and premature birth rates for further description of pregnancy outcome.

Data on relapse, mortality, pregnancy, abortion, preterm delivery were extracted from each identified research, and we computed the log of the ratio and its corresponding standard error for each research. We calculated the random-effects summary estimates by meta-analysis using inverse-variance weighting. Forest plots were formed for each outcome, presenting individual study proportion with $95 \%$ confidence intervals (95\%CIs), as well as the overall pooled estimates showing the corresponding ratio and $95 \%$ CIs. Heterogeneity of the treatment effects was also assessed by $\mathrm{I}^{2}$ analyzed graphically with forest plots. Statistical analysis was performed with R software(America).

To control for the effect of stage on prognosis, we performed a subgroup meta-analysis by stratifying outcomes by stage (IA and IB).

\section{CONFLICTS OF INTEREST}

Authors have nothing to disclose.

\section{GRANT SUPPORT}

This work was supported by the National Clinical Research Center for Gynecological Oncology (2015BAI13B05), National Key Research and Development Program of China (2016YFC1302904), National Natural Science Foundation of China (81502251),Science and Technology Development Project of Shandong Province (2016GSF201164), National Natural Science Foundation of Shandong Province (BS2014SW009)

\section{REFERENCES}

1. Seli E, Tangir J. Fertility preservation options for female patients with malignancies. Current Opinion in Obstetrics \& Gynecology. 2005; 17:299-308.

2. Park JY, Kim DY, Suh DS, Kim JH, Kim YM, Kim YT, Nam JH. Reproductive outcomes after laparoscopic radical trachelectomy for early-stage cervical cancer. Journal of Gynecologic Oncology. 2014; 25:9-13.

3. Sonoda Y, Abu-Rustum NR, Gemignani ML, Chi DS, Brown CL, Poynor EA, Barakat RR. A fertility-sparing alternative to radical hysterectomy: how many patients may be eligible? Gynecologic oncology. 2005; 95:534-538.

4. Dargent D, Martin X, Sacchetoni A, Mathevet P. Laparoscopic vaginal radical trachelectomy: a treatment to preserve the fertility of cervical carcinoma patients. Cancer. 2000; 88:1877-1882.

5. Covens A, Shaw P, Murphy J, DePetrillo D, Lickrish G, Laframboise $\mathrm{S}$, Rosen $\mathrm{B}$. Is radical trachelectomy a safe alternative to radical hysterectomy for patients with stage IA-B carcinoma of the cervix? Cancer. 1999; 86:22732279.

6. Shepherd JH, Mould T, Oram DH. Radical trachelectomy in early stage carcinoma of the cervix: outcome as judged by recurrence and fertility rates. BJOG. 2001; 108:882-885.

7. Plante M, Renaud MC, Francois H, Roy M. Vaginal radical trachelectomy: an oncologically safe fertility-preserving surgery. An updated series of 72 cases and review of the literature. Gynecologic oncology. 2004; 94:614-623.

8. Burnett AF, Roman LD, O'Meara AT, Morrow CP. Radical vaginal trachelectomy and pelvic lymphadenectomy for preservation of fertility in early cervical carcinoma. Gynecologic oncology. 2003; 88:419-423.

9. Pareja R, Rendón GJ, Sanz-Lomana CM, Monzon O, Ramírez PT. Surgical, oncological, and obstetrical outcomes after abdominal radical trachelectomy - a systematic literature review. Gynecologic Oncology. 2013; 131:77-82.

10. Salihi R, Leunen K, Van LE, Moerman P, Neven P, Vergote I. Neoadjuvant chemotherapy followed by large cone resection as fertility-sparing therapy in stage IB cervical cancer. Gynecologic oncology. 2015; 139:447-451.

11. Ditto A, Martinelli F, Bogani G, Fischetti M, Di DV, Lorusso D, Raspagliesi F. Fertility-sparing surgery in earlystage cervical cancer patients: oncologic and reproductive outcomes. International Journal of Gynecological Cancer. 2015; 25:493-497.

12. Fanfani F, Landoni F, Gagliardi ML, Fagotti A, Preti E, Moruzzi MC, Monterossi G, Scambia G. Sexual and Reproductive Outcomes in Early Stage Cervical Cancer Patients after Excisional Cone as a Fertility-sparing Surgery: An Italian Experience. Journal of Reproduction \& Infertility. 2014; 15:29-34.

13. Min CC, Sang GJ, Park H, Sun YL, Chan L, Hwang YY, 
Kim SJ. Fertility preservation by photodynamic therapy combined with conization in young patients with early stage cervical cancer: A pilot study. Photodiagnosis \& Photodynamic Therapy. 2014; 11:420-425.

14. Andikyan V, Khoury-Collado F, Denesopolis J, Sandadi S, Park K, Brown C, Sonoda Y, Chi D, Barakat R, AbuRustum N. Cervical conization and sentinel lymph node mapping in the treatment of stage I cervical cancer: Is less enough? International Journal of Gynecological Cancer. 2014; 24:113-117.

15. Biliatis I, Kucukmetin A, Patel A, Ratnavelu N, Cross P, Chattopadhyay S, Galaal K, Naik R. Small volume stage 1B1 cervical cancer : Is radical surgery still necessary? Gynecologic oncology. 2012; 126:73-77.

16. Maneo A, Sideri M, Scambia G, Boveri S, Dell'Anna T, Villa M, Parma G, Fagotti A, Fanfani F, Landoni F. Simple conization and lymphadenectomy for the conservative treatment of stage IB1 cervical cancer. An Italian experience. Gynecologic oncology. 2011; 123:557-560.

17. Fagotti A, Gagliardi ML, Moruzzi C, Carone V, Scambia G, Fanfani F. Excisional cone as fertility-sparing treatment in early-stage cervical cancer. Fertility \& Sterility. 2011; 95:1109-1112.

18. Baalbergen A, Smedts F, Helmerhorst TJ. Conservative therapy in microinvasive adenocarcinoma of the uterine cervix is justified: an analysis of 59 cases and a review of the literature. International Journal of Gynecological Cancer. 2011; 21:1640-1645.

19. Yahata T, Nishino KK, Sekine M, Fujita K, Sasagawa M, Honma S, Kodama S, Tanaka K. Conservative treatment of stage IA1 adenocarcinoma of the uterine cervix with a long-term follow-up. International Journal of Gynecological Cancer. 2010; 20:1063-1066.

20. Lee SJ, Kim WY, Lee JW, Kim HS, Choi YL, Ahn GH, Lee JH, Kim BG, Bae DS. Conization using electrosurgical conization and cold coagulation for international federation of gynecology and obstetrics stage IA1 squamous cell carcinomas of the uterine cervix. International Journal of Gynecological Cancer. 2009; 19:407-411.

21. Maneo A, Chiari S, Bonazzi C, Mangioni C. Neoadjuvant chemotherapy and conservative surgery for stage IB1 cervical cancer. Gynecologic oncology. 2008; 111:438-443.

22. Bisseling KC, Bekkers RL, Rome RM, Quinn MA. Treatment of microinvasive adenocarcinoma of the uterine cervix: A retrospective study and review of the literature. Gynecologic oncology. 2008; 107:424-430.

23. Landoni F, Parma G, Peiretti M, Zanagnolo V, Sideri M, Colombo N, Maggioni A. Chemo-conization in early cervical cancer. Gynecologic oncology. 2007; 107:125-126.

24. Itsukaichi M, Kurata H, Matsushita M, Watanabe M, Sekine M, Aoki Y, Tanaka K. Stage Ial cervical squamous cell carcinoma: conservative management after laser conization with positive margins. Gynecologic oncology. 2003; 90:387-389.
25. Tseng CJ, Horng SG, Soong YK, Hsueh S, Hsieh CH, Lin HW. Conservative conization for microinvasive carcinoma of the cervix. American Journal of Obstetrics and Gynecology. 1997; 176:1009-1010.

26. Morris M, Mitchell MF, Silva EG, Copeland LJ, Gershenson DM. Cervical Conization as Definitive Therapy for Early Invasive Squamous Carcinoma of the Cervix. Gynecologic oncology. 1993; 51:193-196.

27. Vieira MA, Rendon GJ, Munsell M, Echeverri L, Frumovitz M, Schmeler KM, Pareja R, Escobar PF, Reis RD, Ramirez PT. Radical trachelectomy in early-stage cervical cancer: A comparison of laparotomy and minimally invasive surgery. Gynecologic oncology. 2015; 138:585-589.

28. Hauerberg L, Hogdall C, Loft A, Ottosen C, Bjoern SF, Mosgaard BJ, Nedergaard L, Lajer H. Vaginal Radical Trachelectomy for early stage cervical cancer. Results of the Danish National Single Center Strategy. Gynecologic oncology. 2015; 138:304-310.

29. Lanowska M, Mangler M, Speiser D, Bockholdt C, Schneider A, Kohler C, Vasiljeva J, Al-Hakeem M, Vercellino GF. Radical vaginal trachelectomy after laparoscopic staging and neoadjuvant chemotherapy in women with early-stage cervical cancer over $2 \mathrm{~cm}$ : oncologic, fertility, and neonatal outcome in a series of 20 patients. International journal of gynecological cancer. 2014; 24:586-593.

30. Faber-Swensson AP, Perrin LC, Nicklin JL. Radical trachelectomy for early stage cervical cancer: the Queensland experience. The Australian \& New Zealand journal of obstetrics \& gynaecology. 2014; 54:450-452.

31. Ma LK, Cao DY, Yang JX, Liu JT, Shen K, Lang JH. Pregnancy outcome and obstetric management after vaginal radical trachelectomy. European Review for Medical \& Pharmacological Sciences. 2014; 18:3019-3024.

32. van Gent MD, Lw VDH, Gaarenstroom KN, Peters AA, van Poelgeest MI, Trimbos JB, de Kroon CD. Nerve-sparing radical abdominal trachelectomy versus nerve-sparing radical hysterectomy in early-stage (FIGO IA2-IB) cervical cancer: a comparative study on feasibility and outcome. International Journal of Gynecological Cancer. 2014; 24:735-743.

33. Park JY, Joo WD, Chang SJ, Kim DY, Kim JH, Kim YM, Kim YT, Nam JH. Long-term outcomes after fertilitysparing laparoscopic radical trachelectomy in young women with early-stage cervical cancer: an Asan Gynecologic Cancer Group (AGCG) study. Journal of surgical oncology. 2014; 110:252-257.

34. Kucukmetin A, Biliatis I, Ratnavelu N, Patel A, Cameron I, Ralte A, Naik R. Laparoscopic radical trachelectomy is an alternative to laparotomy with improved perioperative outcomes in patients with early-stage cervical cancer. International journal of gynecological cancer. 2014; 24:135140.

35. Capilna ME, Ioanid N, Scripcariu V, Gavrilescu MM, Szabo B. Abdominal radical trachelectomy: a Romanian 
series. International journal of gynecological cancer Society. 2014; 24:615-619.

36. Lintner B, Saso S, Tarnai L, Novak Z, Palfalvi L, Del PG, Smith JR, Ungar L. Use of abdominal radical trachelectomy to treat cervical cancer greater than $2 \mathrm{~cm}$ in diameter. International Journal of Gynecological Cancer. 2013; 23:1065-1070.

37. Lu Q, Zhang Y, Liu C, Wang S, Guo S, Zhang Z. Total laparoscopic radical trachelectomy in the treatment of early squamous cell cervical cancer: a retrospective study with 8-year follow-up. Gynecologic oncology. 2013; 130:275279.

38. Nishio H, Fujii T, Sugiyama J, Kuji N, Tanaka M, Hamatani T, Miyakoshi K, Minegishi K, Tsuda H, Iwata $\mathrm{T}$. Reproductive and obstetric outcomes after radical abdominal trachelectomy for early-stage cervical cancer in a series of 31 pregnancies. Human Reproduction. 2013; 28:1793-1798.

39. Ebisawa K, Takano M, Fukuda M, Fujiwara K, Hada T, Ota Y, Kurotsuchi S, Kanao H, Andou M. Obstetric outcomes of patients undergoing total laparoscopic radical trachelectomy for early stage cervical cancer. Gynecologic oncology. 2013; 131:83-86.

40. Wethington SL, Sonoda Y, Park KJ, Alektiar KM, Tew WP, Chi DS, Leitao MM Jr, Jewell EL, Barakat RR, Abu-Rustum NR. Expanding the indications for radical trachelectomy: a report on 29 patients with stage IB1 tumors measuring 2 to 4 centimeters. International Journal of Gynecological Cancer. 2013; 23:1092-1098.

41. Cao DY, Yang JX, Wu XH, Chen YL, Li L, Liu KJ, Cui $\mathrm{MH}, \mathrm{Xie} \mathrm{X}, \mathrm{Wu} \mathrm{YM}$, Kong BH. Comparisons of vaginal and abdominal radical trachelectomy for early-stage cervical cancer: preliminary results of a multi-center research in China. British journal of cancer. 2013; 109:2778-2782.

42. Uzan C, Gouy S, Desroque D, Pomel C, Duvillard P, Balleyguier C, Haiemeder C, Morice P. Analysis of a continuous series of 34 young patients with early-stage cervical cancer selected for a vaginal radical trachelectomy: should "staging" conization be systematically performed before this procedure? International Journal of Gynecological Cancer. 2013; 23:331-336.

43. Li J, Wu X, Li X, Ju X. Abdominal radical trachelectomy: Is it safe for IB1 cervical cancer with tumors $>/=2 \mathrm{~cm}$ ? Gynecologic oncology. 2013; 131:87-92.

44. Testa R, Ramirez PT, Ferreyra H, Saadi J, Franco G, Goldsman M, Perrotta M. Abdominal radical trachelectomy: a safe and feasible option for fertility preservation in developing countries. Journal of Lower Genital Tract Disease. 2013; 17:378-384.

45. Muraji M, Sudo T, Nakagawa E, Ueno S, Wakahashi S, Kanayama S, Yamada T, Yamaguchi S, Fujiwara K, Nishimura R. Type II versus type III fertility-sparing abdominal radical trachelectomy for early-stage cervical cancer: a comparison of feasibility of surgical outcomes. International journal of gynecological cancer. 2012; 22:479-
483.

46. Kim CH, Abu-Rustum NR, Chi DS, Gardner GJ, Leitao MM Jr, Carter J, Barakat RR, Sonoda Y. Reproductive outcomes of patients undergoing radical trachelectomy for early-stage cervical cancer. Gynecologic oncology. 2012; 125:585-588.

47. Persson J, Imboden S, Reynisson P, Andersson B, Borgfeldt C, Bossmar T. Reproducibility, accuracy of robot-assisted laparoscopic fertility sparing radical trachelectomy. Gynecologic oncology. 2012; 127:484-488.

48. Raju SK, Papadopoulos AJ, Montalto SA, Coutts M, Culora G, Kodampur M, Mehra G, Devaja O. Fertilitysparing surgery for early cervical cancer-approach to less radical surgery. International journal of gynecological cancerSociety. 2012; 22:311-317.

49. Nick AM, Frumovitz MM, Soliman PT, Schmeler KM, Ramirez PT. Fertility sparing surgery for treatment of early-stage cervical cancer: open vs. robotic radical trachelectomy. Gynecologic oncology. 2012; 124:276-280.

50. Wethington SL, Cibula D, Duska LR, Garrett L, Kim CH, Chi DS, Sonoda Y, Abu-Rustum NR. An international series on abdominal radical trachelectomy: 101 patients and 28 pregnancies. International journal of gynecological cancer. 2012; 22:1251-1257.

51. Saso S, GhaemMaghami S, Chatterjee J, Naji O, Farthing A, Mason P, Mcindoe A, Hird V, Ungar L, Del PG. Abdominal radical trachelectomy in West London. Bjog. 2012; 119:187-193.

52. Plante M, Gregoire J, Renaud MC, Roy M. The vaginal radical trachelectomy: an update of a series of 125 cases and 106 pregnancies. Gynecologic oncology. 2011; 121:290297.

53. Li J, Li Z, Wang H, Zang R, Zhou Y, Ju X, Ke G, Wu X. Radical abdominal trachelectomy for cervical malignancies: surgical, oncological and fertility outcomes in 62 patients. Gynecologic oncology. 2011; 121:565-570.

54. Marchiole P, Tigaud JD, Costantini S, Mammoliti S, Buenerd A, Moran E, Mathevet P. Neoadjuvant chemotherapy and vaginal radical trachelectomy for fertility-sparing treatment in women affected by cervical cancer (FIGO stage IB-IIA1). Gynecologic oncology. 2011; 122:484-490.

55. Speiser D, Mangler M, Kohler C, Hasenbein K, Hertel H, Chiantera V, Gottschalk E, Lanowska M. Fertility outcome after radical vaginal trachelectomy: a prospective study of 212 patients. International journal of gynecological cancer. 2011; 21:1635-1639.

56. Yao $\mathrm{T}, \mathrm{Mo} \mathrm{S}$, Lin $\mathrm{Z}$. The functional reconstruction of fertility-sparing radical abdominal trachelectomy for early stage cervical carcinoma. European journal of obstetrics, gynecology, and reproductive biology. 2010; 151:77-81.

57. Kim JH, Park JY, Kim DY, Kim YM, Kim YT, Nam JH. Fertility-sparing laparoscopic radical trachelectomy for young women with early stage cervical cancer. BJOG. 
2010; 117:340-347.

58. Shepherd JH. Challenging dogma: radical conservation surgery for early stage cervical cancer in order to retain fertility. Annals of the Royal College of Surgeons of England. 2009; 91:181-187.

59. Olawaiye A, Carmen MD, Tambouret R, Goodman A, Fuller A, Duska LR. Abdominal radical trachelectomy: Success and pitfalls in a general gynecologic oncology practice. Gynecologic oncology. 2009; 112:506-510.

60. Cibula D, Slama J, Svarovsky J, Fischerova D, Freitag P, Zikan M, Pinkavova I, Pavlista D, Dundr P, Hill M. Abdominal radical trachelectomy in fertility-sparing treatment of early-stage cervical cancer. International journal of gynecological cancer. 2009; 19:1407-1411.

61. Nishio H, Fujii T, Kameyama K, Susumu N, Nakamura M, Iwata T, Aoki D. Abdominal radical trachelectomy as a fertility-sparing procedure in women with early-stage cervical cancer in a series of 61 women. Gynecologic oncology. 2009; 115:51-55.

62. Diaz JP, Sonoda Y, Leitao MM, Zivanovic O, Brown CL, Chi DS, Barakat RR, Abu-Rustum NR. Oncologic outcome of fertility-sparing radical trachelectomy versus radical hysterectomy for stage IB1 cervical carcinoma. Gynecologic oncology. 2008; 111:255-260.

63. Milliken DA, Shepherd JH. Fertility preserving surgery for carcinoma of the cervix. Current Opinion in Oncology. 2008; 20:575-580.

64. Pareja FR, Ramirez PT, Borrero FM, Angel CG. Abdominal radical trachelectomy for invasive cervical cancer: a case series and literature review. Gynecologic oncology. 2008; 111:555-560.

65. Shepherd JH, Spencer C, Herod J, Ind TE. Radical vaginal trachelectomy as a fertility-sparing procedure in women with early-stage cervical cancer-cumulative pregnancy rate in a series of 123 women. BJOG. 2006; 113:719-724.

66. Chen Y, Xu H, Zhang Q, Li Y, Wang D, Liang Z. A fertility-preserving option in early cervical carcinoma: laparoscopy-assisted vaginal radical trachelectomy and pelvic lymphadenectomy. European journal of obstetrics, gynecology, and reproductive biology. 2008; 136:90-93.

67. Ungar L, Palfalvi L, Hogg R, Siklos P, Boyle DC, Del Priore G, Smith JR. Abdominal radical trachelectomy: a fertility-preserving option for women with early cervical cancer. BJOG. 2005; 112:366-369.

68. Schlaerth JB, Spirtos NM, Schlaerth AC. Radical trachelectomy and pelvic lymphadenectomy with uterine preservation in the treatment of cervical cancer. American Journal of Obstetrics and Gynecology. 2003; 188:29-34.

69. Frumovitz M, dos Reis R, Sun CC, Milam MR, Bevers MW, Brown J, Slomovitz BM, Ramirez PT. Comparison of total laparoscopic and abdominal radical hysterectomy for patients with early-stage cervical cancer. Obstetrics and gynecology. 2007; 110:96-102.

70. Obermair A, Gebski V, Frumovitz M, Soliman PT,
Schmeler KM, Levenback C, Ramirez PT. A Phase III Randomized Clinical Trial Comparing Laparoscopic or Robotic Radical Hysterectomy with Abdominal Radical Hysterectomy in Patients with Early Stage Cervical Cancer. Journal of Minimally Invasive Gynecology. 2008; 15:584588.

71. Rob L, Skapa P, Robova H. Fertility-sparing surgery in patients with cervical cancer. Lancet Oncology. 2011; 12:192-200.

72. Ramirez PT, Schmeler KM, Soliman PT, Frumovitz M. Fertility preservation in patients with early cervical cancer: Radical trachelectomy. Gynecologic oncology. 2008; 110:25-28.

73. Gien LT, Covens A. Fertility-sparing options for early stage cervical cancer. Gynecologic oncology. 2010; 117:350-357.

74. Burnett AF. Radical trachelectomy with laparoscopic lymphadenectomy: review of oncologic and obstetrical outcomes. Current Opinion in Obstetrics \& Gynecology. 2006; 18:8-13.

75. Beiner ME, Covens A. Surgery insight: radical vaginal trachelectomy as a method of fertility preservation for cervical cancer. Nature Clinical Practice Oncology. 2007; 4:353-361.

76. Wethington S, Cibula D, Duska L, Garrett L, Kim C, Sonoda Y, Abu-Rustum N. An international series on abdominal trachelectomy: 101 patients and 28 pregnancies. International Journal of Gynecological Cancer. 2012; 22:1251-1257.

77. Pareja R, Rendón GJ, Vasquez M, Echeverri L, SanzLomana CM, Ramirez PT. Immediate radical trachelectomy versus neoadjuvant chemotherapy followed by conservative surgery for patients with stage IB1 cervical cancer with tumors $2 \mathrm{~cm}$ or larger: A literature review and analysis of oncological and obstetrical outcomes. Gynecologic oncology. 2015; 137:141-142.

78. Pluta M, Rob L, Charvat M, Chmel R, Halaska M, Skapa P, Robova H. Less radical surgery than radical hysterectomy in early stage cervical cancer - A pilot study. Gynecologic oncology. 2009; 113:181-184.

79. Schmeler KM, Frumovitz M, Ramirez PT. Conservative management of early stage cervical cancer: Is there a role for less radical surgery? Gynecologic oncology. 2011; 120:321-325.

80. Lindsay R, Burton K, Shanbhag S, Tolhurst J, Millan D, Siddiqui N. Fertility conserving management of early cervical cancer: our experience of LLETZ and pelvic lymph node dissection. International Journal of Gynecological Cancer. 2013; 24:118-123.

81. Slim K, Nini E, Forestier D, Kwiatkowski F, Panis Y, Chipponi J. Methodological index for non-randomized studies ( MINORS ): development and validation of a new instrument. Anz Journal of Surgery. 2003; 73:712-716. 